\title{
Editorial
}

\section{Grad+ Segue seu Curso: Fluência e Profundidade}

\author{
Prof. Thiago Mio Salla e Prof. Eder Cassola Molina
}

Fruto do I Congresso de Graduação da USP, ganhava vida, há pouco mais de dois anos, a revista Grad+. Desde então, embora independente, o periódico se nutre do rio caudaloso que esse evento paradigmático propiciou, ao levar para as suas páginas (com todo o zelo editorial requerido por sua missão) o que de melhor a academia produz em termos de pesquisas teóricas e empíricas, experiências pedagógicas e práticas de ensino no âmbito da graduação. Em sua maioria, tais iniciativas encontravam-se ocultas e represadas, não encontrando, assim, espaço adequado para se manifestarem, nem, muito menos, para convergirem e ganharem a um só tempo visibilidade e profundidade.

Tendo tal diretriz em vista, no momento em que chegamos à quarta edição do Congresso de Graduação da USP, Grad + oferta aos leitores seu sétimo número. Na capa, conferimos destaque ao artigo "Considerações Sobre o Uso de Mapas na Web Para o Ensino de Ciência do Solo", no qual seus autores defendem o uso de Tecnologias de Informação e Comunicação (TICs) para o ensino de Pedologia, tomando como base os mapas interativos disponibilizados pelo Instituto Brasileiro de Geografia e Estatística (IBGE). Depois de fazer um levantamento das ementas das disciplinas que tratavam de ciência do solo em diferentes universidades brasileiras e de realizar um exame detido das ferramentas cartográficas ofertadas pelo site do IBGE, concluem, metonimicamente, que as TICs devem ser adotadas em sala de aula não por uma demanda pura e simples de atualização tecnológica, mas sim de acordo com as necessidades pedagógicas requeridas pelo conteúdo ministrado e desejadas pelo professor.

Se a educação superior pública se abre a propostas de ensino modernas e inovadoras, ao mesmo tempo ela deve orientar-se pelos interesses da coletividade, tendo em vista o papel da universidade em promover o desenvolvimento social e econômico do país. Considerando-se essa premissa, logo em seguida ganha espaço um artigo que discorre sobre a reestruturação curricular realizada pela graduação em Odontologia da Faculdade de Odontologia da USP, processo esse que se pautou não só pelo Plano Nacional de Educação e pelas Diretrizes Curriculares Nacionais para a área em questão, mas também por políticas nacionais de saúde, com destaque para o Programa Nacional de Reorientação da Formação Profissional em Saúde (Pró-Saúde) e o Programa de Educação pelo Trabalho em Saúde (PET Saúde). Mais especificamente, ao tratarem da reforma da grade do curso com ênfase na disciplina de Odontopediatria, os autores procuraram apreciar o desempenho e a percepção dos estudantes em relação às mudanças implementadas, confirmando tanto a melhora no aprendizado do corpo discente quanto a avaliação positiva deste no que se refere às alterações realizadas.

Por outro lado, partindo da constatação de que o Subsistema de Saúde Suplementar brasileiro (setor caracterizado pela atuação dos planos privados de saúde) seria pouco explorado pelos cursos de graduação da área em questão, um pool de docentes da Escola de Enfermagem de Ribeirão Preto (USP) investigou as grades curriculares de nove cursos de graduação do campus da USP de Ribeirão Preto (Medicina, Enfermagem, Odontologia, Farmácia, Nutrição, Fisioterapia, Fonoaudiologia, Terapia Ocupacional e Psicologia). Com base no levantamento realizado, as autoras diagnosticaram a referida omissão e, em chave propositiva, sinalizam a importância de repensar os currículos das graduações examinadas, de modo a contemplar tal setor privado, algo relevante para que o futuro profissional possa "operar corretamente o direito à saúde". 
Ainda na área de ciências biológicas, este número apresenta artigo de um grupo de professoras e pesquisadoras da Faculdade de Medicina Veterinária e Zootecnia da USP que trata do ensino de anatomia, disciplina fundamental na formação dos profissionais de saúde. Depois de apresentarem com minudência quatro tendências pedagógicas relativas à docência de tal matéria, as autoras concluem que a melhor metodologia de ensino-aprendizagem de anatomia veterinária tende a ser aquela em que coexistam, de maneira complementar, recursos tecnológicos e dissecação animal.

Das ciências exatas, chamam a atenção dois artigos de caráter transversal. No primeiro deles, tematiza-se a medição de desempenho em cursos de graduação enquanto uma importante ferramenta de gestão, capaz de subsidiar as decisões dos diferentes agentes vinculados a instituições de ensino superior quanto a políticas e a investimentos. Mais especificamente, os autores propõem um sistema de medição de desempenho para o curso de Engenharia de Produção da Poli/USP, cujas bases podem ser replicadas em outros contextos e áreas.

No segundo artigo acima mencionado, toma o lugar o exame da percepção docente sobre a aplicação do Problem Based Learning (PBL) como estratégia de ensino em cursos de Contabilidade. A partir de entrevistas semiestruturadas, os autores da pesquisa detectaram uma falha na formação pedagógica dos professores, na medida em que todos estes foram unânimes em declarar que conheceram o PBL apenas depois de começarem a atuar no magistério. Em resumo, o texto traz um novo enfoque em torno do uso dessa metodologia ativa de ensino-aprendizagem que já foi alvo de diversos artigos e relatos estampados nas edições anteriores de Grad+.

Para fechar a seção de artigos, um conjunto de docentes e pesquisadores da Faculdade de Odontologia de Bauru apresentam os resultados de uma extensa pesquisa cujo objetivo se centrou em conhecer o perfil dos alunos de Ensino Médio e de cursinhos pré-vestibular com interesse de ingressar em algum curso superior. Ao entrevistarem mais de cem estudantes de escolas públicas e particulares, os autores procuraram mapear dados sobre a idade, o nível socioeconômico e as preferências de áreas de estudo da população investigada. Ao final, apresentam-se dados relevantes sobre os fatores que mais influenciam a escolha da profissão e da graduação a ser cursada por parte de nossos futuros calouros.

Por fim, entre os relatos, assim como em todas as edições passadas de Grad+, pululam experiências pedagógicas provenientes dos mais variados cursos, instituições e áreas, por mais que neste número em específico haja prevalência, todavia, de trabalhos provenientes das ciências biológicas. De início, conferimos destaque para um texto em inglês que tematiza o papel de aulas práticas e contextualizadas no ensino de Bioquímica e a correlação de conhecimentos adquiridos em outras disciplinas na graduação em Farmácia. De modo análogo, a importância da dimensão prática da aprendizagem avulta em trabalhos sobre o diagnóstico do abdômen agudo e o ensino de genética molecular. Alguns autores relatam suas experiências na realização de oficinas de planejamento em saúde, descrevem atividades de acompanhamento pedagógico e apoio a graduandos ou tratam do papel da iniciação científica no avanço na fronteira do conhecimento em relação às ciências básicas e no uso de modelos animais na pesquisa experimental. Outros destacam o uso de simuladores realísticos na transmissão de conhecimentos sobre fisiologia humana, bem como o estudo da cultura corporal na formação de pedagogos ou ainda a aplicação de metodologias ativas no ensino de Direito. Finalmente, há professores que traçam o perfil dos egressos em Fisioterapia da Faculdade de Medicina da USP, realizando um trabalho de mapeamento fundamental que poderia ser replicado em outros contextos.

Tal como se pode perceber pelo conjunto multifacetado e amplo de temas e assuntos que oferecemos aos leitores neste número de Grad+, a revista continua a permitir que ganhe fluência, corpo e substância toda uma gama de reflexões teórico-metodológicas de relevo, capazes de materializar o engajamento docente na busca de técnicas e práticas que promovam um modelo de ensino a um só tempo qualificado e hodierno, distante do modelo de educação "bancária". 
Se, até o presente momento, temos trabalhado com a edição de artigos e relatos que nos chegam em fluxo contínuo, tal expediente será ampliado a partir de agora mediante a abertura de chamadas para a publicação de novos textos nos números que virão. Oxalá, esperamos assim que nosso rio piscoso nunca cesse de correr e que suas águas, ainda que modestamente, continuem a fecundar o ensino de graduação em nosso país, orientando-se sempre por uma perspectiva plural, democrática e crítica. 